\title{
Along-strike variation in slab geometry at the southern Mariana subduction zone revealed by seismicity through ocean bottom seismic experiments
}

\author{
Gaohua Zhu ${ }^{\odot},{ }_{1}$ Hongfeng Yang ${ }^{\odot},{ }^{1}$ Jian Lin ${ }^{\odot},{ }^{2,3}$ Zhiyuan Zhou, ${ }^{2}$ Min Xu, ${ }^{2}$ Jinlong Sun ${ }^{2}$ \\ and Kuiyuan Wan ${ }^{2}$ \\ ${ }^{1}$ Earth System Science Programme, Faculty of Science, the Chinese University of Hong Kong, Shatin, Hong Kong, China. \\ E-mail: hyang@cuhk.edu.hk,jlin@whoi.edu \\ ${ }^{2}$ Key Laboratory of Ocean and Marginal Sea Geology, South China Sea Institute of Oceanology, Chinese Academy of Sciences, Guangzhou 510301, China \\ ${ }^{3}$ Department of Geology and Geophysics, Woods Hole Oceanographic Institution, Woods Hole, MA 02543, USA
}

Accepted 2019 June 9. Received 2019 May 18; in original form 2018 December 5

\begin{abstract}
SUMMAR Y
We have conducted the first passive Ocean Bottom Seismograph (OBS) experiment near the Challenger Deep at the southernmost Mariana subduction zone by deploying and recovering an array of 6 broad-band OBSs during December 2016-June 2017. The obtained passive-source seismic records provide the first-ever near-field seismic observations in the southernmost Mariana subduction zone. We first correct clock errors of the OBS recordings based on both teleseismic waveforms and ambient noise cross-correlation. We then perform matched filter earthquake detection using 53 template events in the catalogue of the US Geological Survey and find $>7000$ local earthquakes during the 6-month OBS deployment period. Results of the two independent approaches show that the maximum clock drifting was $\sim 2 \mathrm{~s}$ on one instrument (OBS PA01), while the rest of OBS waveforms had negligible time drifting. After timing correction, we locate the detected earthquakes using a newly refined local velocity model that was derived from a companion active source experiment in the same region. In total, 2004 earthquakes are located with relatively high resolution. Furthermore, we calibrate the magnitudes of the detected earthquakes by measuring the relative amplitudes to their nearest relocated templates on all OBSs and acquire a high-resolution local earthquake catalogue. The magnitudes of earthquakes in our new catalogue range from 1.1 to 5.6. The earthquakes span over the Southwest Mariana rift, the megathrust interface, forearc and outer-rise regions. While most earthquakes are shallow, depths of the slab earthquakes increase from $\sim 100$ to $\sim 240 \mathrm{~km}$ from west to east towards Guam. We also delineate the subducting interface from seismicity distribution and find an increasing trend in dip angles from west to east. The observed along-strike variation in slab dip angles and its downdip extents provide new constraints on geodynamic processes of the southernmost Mariana subduction zone.
\end{abstract}

Key words: Seismicity and tectonics; Dynamics: seismotectonics; Subduction zone processes.

\section{INTRODUCTION}

The Mariana subduction zone is part of the Izu-Bonin-Mariana (IBM) subduction system, a classical example of intraoceanic convergent margin that was first formed $\sim 43 \mathrm{Ma}$ (Katsumata \& Sykes 1969; Gribble et al. 1996; Stern et al. 2003). The old incoming Pacific Plate is considered to sink nearly vertically beneath the trench (Katsumata \& Sykes 1969; Nakamura et al. 1998). Indeed, the steep subducting angle is regarded as characteristic of the Mariana subduction zone. As illustrated by distribution of intermediate and deep earthquakes, the maximum depth of seismicity extends from $\sim 250 \mathrm{~km}$ in the south to $\sim 600 \mathrm{~km}$ in the north, delineating the subducting slab geometries that are consistent with seismic tomographic images (Gudmundsson \& Sambridge 1998; Fryer et al. 2003; Miller et al. 2006). In comparison, the distribution of local earthquakes derived from near-field seismic observations show that the dip angle is $\sim 21^{\circ}$ at the shallow megathrust in the central Mariana subduction zone, much smaller than the illustration of a nearly vertical slab at greater depths (Emry et al. 2011). Therefore, precise 
earthquake locations are critical for delineating subducting slab and further understanding subduction zone dynamics.

However, due to the paucity of local seismic stations, historical earthquake locations along the Mariana subduction zone may have lateral uncertainties up to tens of km (Emry et al. 2011), making it difficult to delineate the shallow megathrust and to consequently infer the dynamics of the shallow subduction zone. Furthermore, large uncertainties in earthquake locations obscure the stress state that can be inferred from focal mechanism solutions of moderate to large earthquakes in the region (Emry et al. 2011; Ekström et al. 2012; Martinez et al. 2018). A near-field seismic network is necessary to acquire precise earthquake locations, but is only available in the central Mariana subduction zone where three Ocean Bottom Seismograph (OBS) experiments were carried out in 2001, 2003 and 2012, respectively (Pyle et al. 2010; Shiobara et al. 2010; Emry et al. 2011; Barklage et al. 2015; Cai et al. 2018).

Compared to the central segment, the southern Mariana subduction zone (the area south of the latitude of Guam at $\sim 13.5^{\circ} \mathrm{N}$ ) remains poorly known since there is no near-field observation, although the southern part is suggested to be more seismically coupled (Scholz \& Campos 1995, 2012; Emry et al. 2014). This is especially true near the Challenger Deep, the deepest point on the Earth's surface (at depth of $\sim 10.9 \mathrm{~km}$ ), as the closest land station (GUMO station at the Guam Island) is more than $350 \mathrm{~km}$ in distance. To fill the near-field observational gap at the southern Mariana subduction zone, we conduct an OBS experiment near the Challenger Deep and obtain the first data set of 6-month local seismic observations (Fig. 1a).

In this study, we use the first near-field OBS observations together with the GUMO land station to obtain a relatively precise local earthquake catalogue during December 2016-June 2017 in the southernmost Mariana margin. Using the OBS recordings, we first detect local earthquakes using template earthquakes in the US Geological Survey (USGS) catalogue. We then inspect and correct the time drifting of OBS recordings, based on both teleseismic waveforms and ambient noise cross-correlation. Next we conduct both absolute and relative earthquake location using a newly acquired local velocity model (Wan et al. 2019). We also calibrate the magnitudes of all located earthquakes by measuring relative amplitudes to their nearest templates on all OBSs. Our results produce the first high-resolution earthquake catalogue in the southernmost Mariana subduction zone, which provides valuable constraints on the geometry of subducting slab and subduction zone dynamics.

\section{EXPEDITIONS AND OBS EXPERIMENTS}

The first 'Challenger Deep' expedition was conducted by the R/V Shiyan 3 of the South China Sea Institute of Oceanology (SCSIO) in December 2016, in which a variety of multidisciplinary experiments were carried out, including physical oceanography, sediment sampling, gravity and magnetic measurements, and active and passive source seismic survey (Lin et al. 2017; Li et al. 2019). The active source seismic experiment lasted 2 weeks from 1 December 2016 with 18 OBSs deployed along a $~ 350-\mathrm{km}$-long NW-SE-trending profile across the Challenger Deep (Fig. 1a). A 2-D crustal $P$-wave velocity model was obtained based on wide-angle reflection and refraction study (Wan et al. 2019).

During the first expedition in December 2016, we also deployed 7 long-term broad-band OBSs on the overriding plate to record earthquakes (Fig. 1a). The OBSs were equipped with three-component sensors, with a response band from $60 \mathrm{~s}$ to $50 \mathrm{~Hz}$, and a hydrophone. The sampling rate of digital recorders was 100 samples per second. In June 2017, we carried out the second expedition to the southernmost Mariana Trench and successfully recovered 6 long-term OBSs. During the 6-month deployment period, 53 local earthquakes (Fig. 1a) and $49 M>6$ teleseismic earthquakes (Fig. 1b) were reported in the USGS catalogue.

\section{INSPECTION AND CORRECTION OF OBS TIMING}

\subsection{Inspection of OBS timing from teleseismic earthquakes}

Accurate timing of seismic recording is critical for earthquake locations. The synchronization with Global Positioning System (GPS) is one option for on-land deployments. However, this does not work for typical OBS deployments, as electromagnetic signals cannot propagate far in water (Gouédard et al. 2014). The timing of an OBS recording depends on its own internal clock, which is only synchronized with GPS before deployment and after recovery. Large timing error might arise from glitches with the clock or data logger (Le et al. 2018). Therefore, we corrected timing errors of each OBS prior to locating earthquakes.

We initially used teleseismic earthquake recordings to evaluate the timing. For teleseismic earthquakes from nearby locations, travel times of one seismic phase should be similar on all OBSs due to similar source-receiver paths. The differences in travel times of the phase between OBSs stem from seismic array geometry, local velocity structure and possible time drifting of OBSs. If there is no time drifting, the differential travel time between two OBSs is only caused by local velocity structure and thus should remain stable over time. To reduce the potential hand-picked travel time errors, we only used teleseismic earthquakes that generated clear impulsive $P$ arrivals. In total nine teleseismic earthquakes nearly spanning most of the deployment period met our selection criteria and were divided into three groups according to their azimuths and locations (Fig. 2d).

We chose one OBS (PA02) as the reference station. For each earthquake, the differential times of $P$-wave between PA02 and other OBSs were calculated by waveform cross-correlation. In addition to differential times between OBSs, we also calculated the differential time between PA02 and the closest permanent land station, GUMO. We then plotted the differential times with their occurrence dates (Figs $2 \mathrm{a}-\mathrm{c}$ ). The differential times of the OBS PA03, PA06, PA07, PA09 and the GUMO station were stable, indicating subtle time drifting of these stations. In contrast, the differential times of PA01 showed a linear drifting relative to other stations, indicating a timing problem of the PA01 OBS station. We also selected other OBS and GUMO as the reference station and found that the trend of differential time between two specific stations did not depend on the choice of the reference station.

\subsection{OBS timing correction using ambient noise cross-correlation}

To accurately estimate the timing shift of OBSs, we then adopted time symmetry analysis using ambient noise cross-correlation functions (NCCF, Stehly et al. 2007; Gouédard et al. 2014; Le et al. 2018). Cross-correlation of a diffuse field yields empirical Green's functions of the medium between two receivers (Shapiro et al. 2005; 


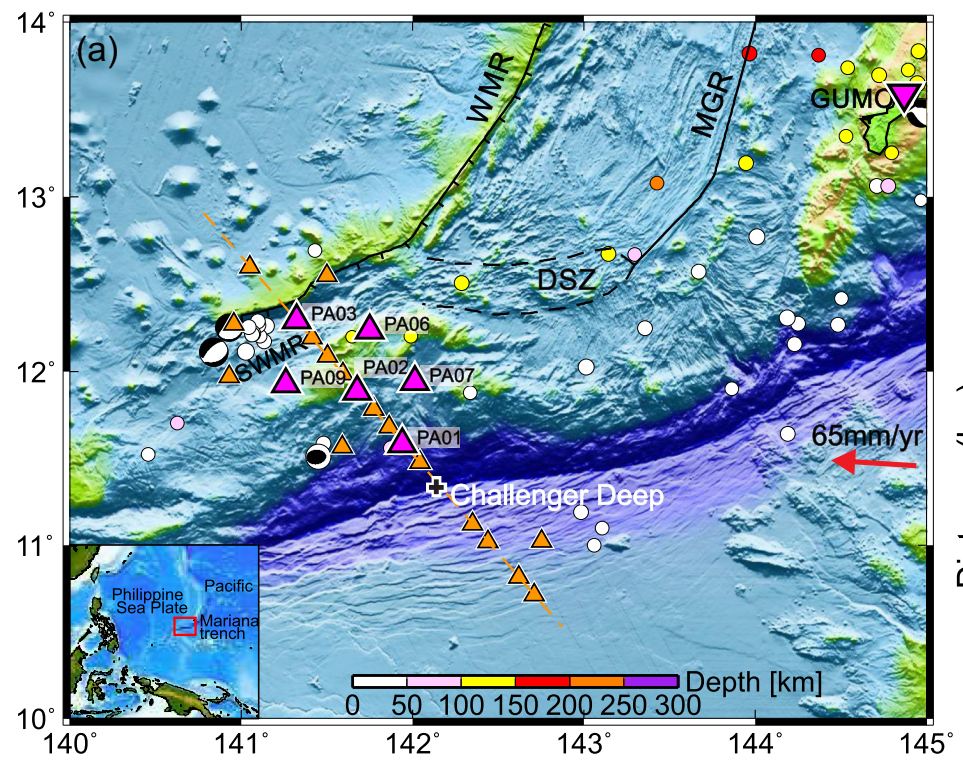

(b)

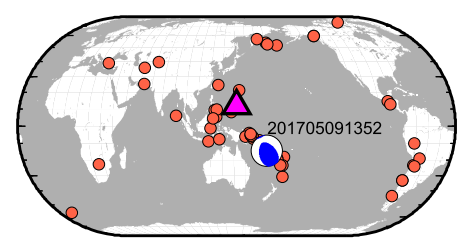

(c)

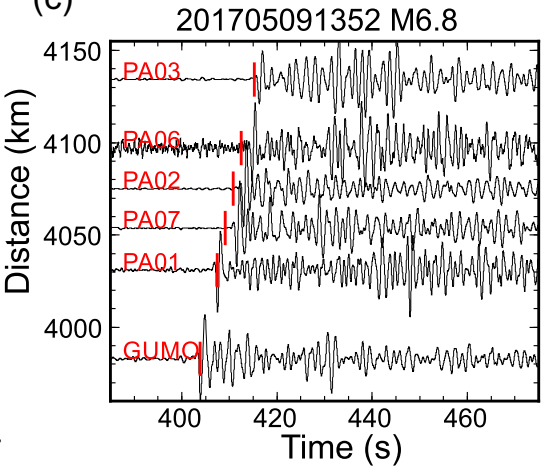

Figure 1. (a) Locations of Ocean Bottom Seismgraph (OBS, triangles) deployed and recovered in two Mariana expeditions. The orange dashed line shows the profile of multichannel seismic reflection using air-gun source. Orange triangles denote OBSs deployed during 1-16 December 2017, while magenta ones show long-term OBS that were deployed between 15 December 2016 and 12 June 2017. Earthquakes in the USGS catalogue (circles) during the 6-month deployment are coloured by depth. Focal mechanism solutions are from Global Centroid Moment Tensor (GCMT) catalogue. Red arrow shows the convergent direction of Pacific Plate relative to the fore arc (Kato et al. 2003). WMR, West Mariana Ridge; SWMR, Southwest Mariana rift; MGR, Malaguana-Gadao Ridges; DSZ, Diffuse spreading zone (Martinez et al. 2018). Inset: Location of the study area (red frame). (b) A map showing distribution of $M>6$ earthquakes (orange circles) during the deployment of OBS (magenta triangle). The waveform profile of the earthquake with blue focal mechanism is shown in panel (c). (c) Waveform profiles of a $M 6.8$ earthquake the focal mechanism of which is shown in panel (b). Red bars indicate theoretical travel times of $P$ waves based on the IASP91 velocity model.

(a) Differential times relative to OBS PA02

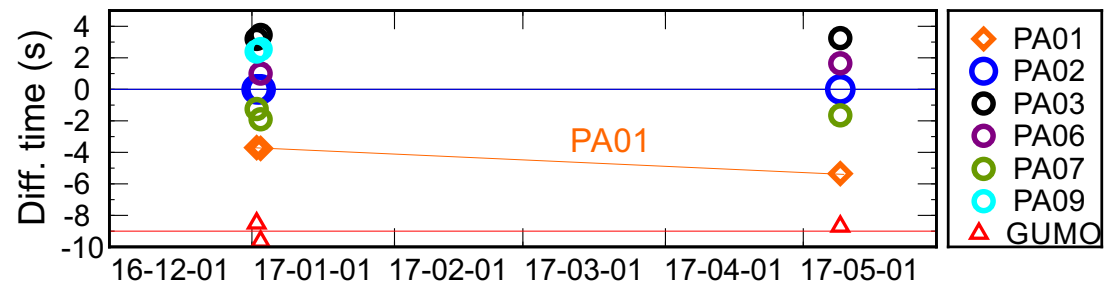

(b)

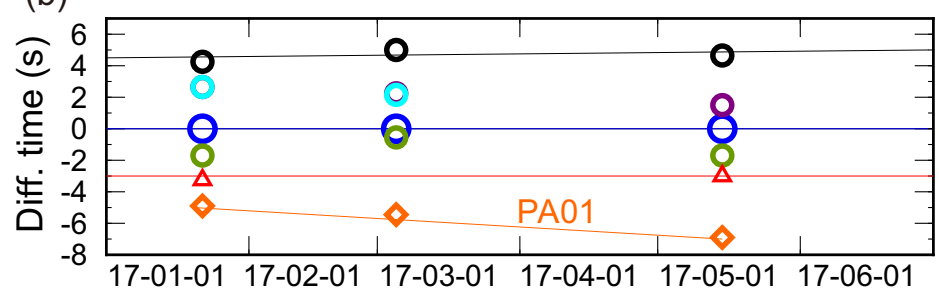

(c)

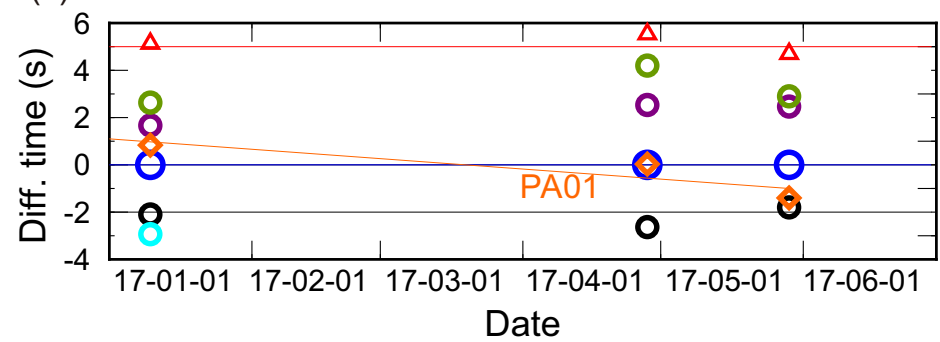

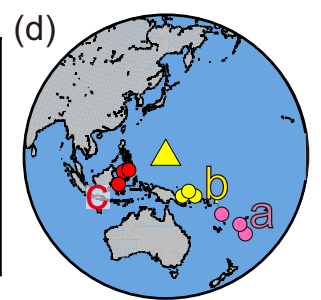

$30 \widehat{\mathrm{o}}$

$28 \stackrel{2}{\supset}$

26

$24 \stackrel{\xi}{\mathrm{\xi}}$

22 這

Figure 2. (a-c) Differential times of $P$ arrivals between OBSs and the reference station (PA02) for three groups of earthquakes from different backazimuths (d). 
Yao et al. 2006; Bensen et al. 2007). If the noise field is isotropic, a NCCF is symmetric in time, with positive and negative times corresponding to causal and acausal waveforms, respectively (Stehly et al. 2007; Gouédard et al. 2014). Otherwise amplitudes of causal and acausal waveforms may differ, but positive and negative times should stay symmetric (Gouédard et al. 2014). If there are any time drifting in receivers, the time symmetry of NCCF will be broken (Stehly et al. 2007; Gouédard et al. 2014). Therefore, we could characterize the relative clock error based on the time symmetry of NCCF between station pairs.

We preferentially used the hydrophone recordings because they provided higher signal-to-noise ratio (SNR) in NCCF than seismometers (Le et al. 2018). Since the hydrophone at PA09 station was not functional, we used the vertical component of PA09 OBS to calculate the NCCF with other vertical components. Daily recordings were divided into segments of $2 \mathrm{hr}$ to compute the NCCF. After applying a $2-5 \mathrm{~s}$ bandpass filter to continuous data, we adopted the temporal normalization cross-correlation method to reduce the disturbance of seismic waveforms (Bensen et al. 2007). To enhance the SNR, we stacked the NCCF of $11 \mathrm{~d}(5 \mathrm{~d}$ before and 5 $\mathrm{d}$ after) and slid the time window for the entire deployment period. The stacked NCCF were then aligned by date. Subtle changes in the lag time of the largest amplitudes indicate negligible relative time drifting (Fig. 3a). Otherwise, temporal evolution of lag time can be attributed to relative clock errors between two stations (Fig. 3b). We calculated temporal evolution of lag time by crosscorrelating NCCF with the first NCCF, and then plotted them versus date (Fig. 4).

After analysis of all NCCF pairs, we found that a linear time drifting was discernible between PA01 and other OBSs, indicating relative clock errors between PA01 and other OBSs (Fig. 4). In contrast, the relative clock errors between OBS PA02, PA03, PA06, PA07 and PA09 were close to zero, indicating subtle relative time error of these stations (Fig. 4). Combined with the analysis of teleseismic waveforms, we concluded that the PA01 station had clock error, with maximum time drifting of $\sim 2 \mathrm{~s}$. The clock errors of OBSs were well consistent with the results obtained by teleseismic waveforms. Therefore, we adopted a linear time correction for PA01 and ignored time errors of other OBSs, which should be much smaller.

\section{EARTHQUAKE DETECTION AND RELOCATION}

\subsection{Earthquake detection}

To find missing earthquakes, we detected local earthquakes by crosscorrelating continuous waveform data with template waveforms using the sliding-window cross-correlation (SCC) detection technique (Yang et al. 2009). We initially selected 53 local catalogue earthquakes during the observation period as template earthquakes (Fig. 1a), whose magnitudes range from 3.9 to 5.6. To maximize the number of detected earthquakes, we conducted the SCC detection using three components of waveforms on a single station. For each template earthquake, waveforms of the nearest OBS were used. If the waveforms on the nearest OBS were noisy, we then used the waveforms of the second nearest OBS.

A 2-8 Hz bandpass filter was applied to both template waveforms and continuous waveforms. We used a 10 -s time window of template waveforms ( $2 \mathrm{~s}$ before and $8 \mathrm{~s}$ after the $S$ arrival). The threshold value of SCC coefficient was 0.5 . We then estimated the origin times of detected earthquakes based on detection times. The initial locations of the detected earthquakes were assumed to be identical to the template earthquakes. The magnitude of the detected event was calculated based on the ratio $(R)$ of the maximum amplitude between the template and detected events on the selected single station:

$M_{\text {detected }}=M_{\text {template }}+c * \log _{10}(R)$,

where $c$ is a constant linking magnitude and amplitude. For local magnitude, the $c$ value of 1.0 is used in most studies, indicating that a tenfold increase in amplitude corresponds to one unit increase in magnitude (Yang et al. 2009; Benz et al. 2015). In our study, the magnitude was determined based on body wave amplitude $\left(m_{b}\right)$ rather than local magnitude of the template events. By analogy with the procedure for local magnitude, we simply took $c=1$ during detection for the initial estimation, although $m_{b}$ was measured at slightly lower frequency than our filter band.

After visual inspection to discard false detections, a total of 2150 events were identified. We then repeated the cross-correlation process with the newly detected earthquakes serving as new template earthquakes. After two iterations of earthquake detection and visual inspection to remove false detections, we eventually obtained 7634 local earthquakes with magnitudes ranging from -1 to 5.6, the total number of which is two orders of magnitude more than that in the USGS catalogue.

\subsection{Earthquake location}

\subsubsection{Layered 1-D velocity model in the southernmost Mariana}

We derived a 1-D local velocity model (red line in Fig. 5) based on the crust1.0 model (Laske et al. 2013) and the newly acquired 2-D crustal $P$-wave velocity model, which was derived from seismic reflection data (Wan et al. 2019). We obtained a 1-D continuous velocity model by averaging the $2-\mathrm{D}$ model at the same depth. We then modified the layered crust 1.0 velocity using the average value of the 1-D continuous model in each layer at depths shallower than $20 \mathrm{~km}$ where the new model had good constraints (Wan et al. 2019). The $V_{s}$ was estimated by $V_{p} / 1.75$. The mantle velocity follows the AK135 velocity model (Kennett et al. 1995). Our modified velocity model is shown in Table 1.

\subsubsection{Absolute earthquake location using Hypoinverse2000}

We then obtained absolute locations for earthquakes with clear arrivals on at least four stations using Hypoinverse2000 (Klein 2002). In addition to our OBS stations, we also used available arrival times at the GUMO station. After applying a 2-8 Hz bandpass filter to the data, we manually picked $4447 P$ and $5172 S$ phases. The distance weighting function was 1.0 for stations closer than $300 \mathrm{~km}$, followed a cosine taper, and then decreased to 0.0 for stations farther than $600 \mathrm{~km}$. The residual weighting function was 1.0 for residuals $<0.5 \mathrm{~s}, 0$ for residuals $>2 \mathrm{~s}$, and also followed a cosine taper in between (Klein 2002). For absolute location, we adopted the criterion that both the horizontal and vertical errors were less than $50 \mathrm{~km}$.

A total of 1248 events were located by Hypoinverse2000. The average time residual was reduced from 3.22 to $0.34 \mathrm{~s}$ after relocation, indicating significant improvement in these earthquake locations. The average horizontal and vertical uncertainties of all absolute locations were 6.3 and $14.5 \mathrm{~km}$, respectively. For events near the OBS 

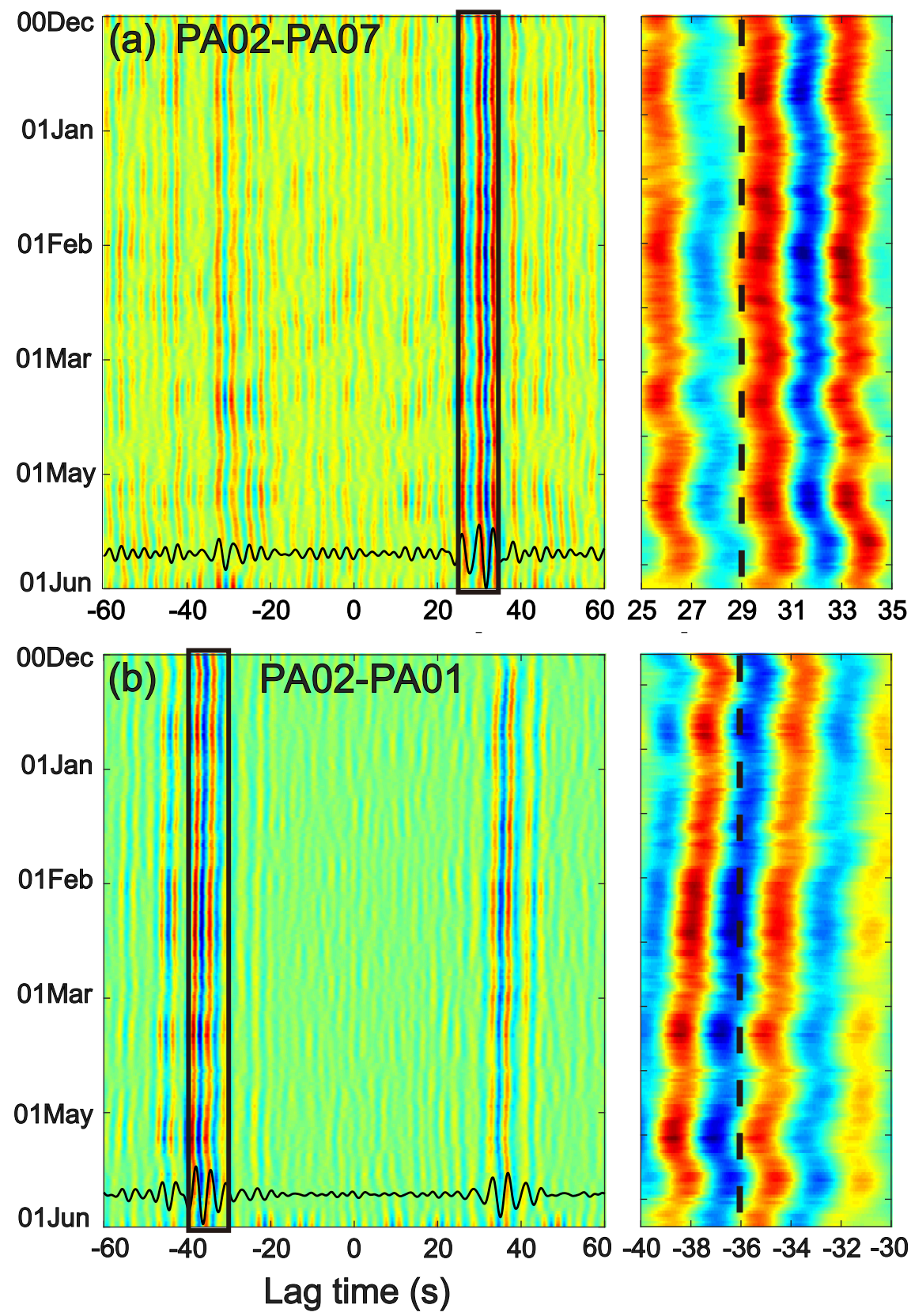

Figure 3. Noise cross-correlation functions (NCCF) from hydrophone recordings at two OBS pairs, with colour indicating the amplitudes of the NCCF. (a) Very little change in arrival time of the largest amplitude, whose zoom-in window is shown in the right-hand panel. Black trace is the stacked NCCF over all days. (b) Clear time drifting indicated by the change of the NCCF between PA02 and PA01 stations.

stations such as the earthquakes along the BB' profile (Fig. 6b), the uncertainties were smaller, $4.3 \mathrm{~km}$ in lateral direction and $13.3 \mathrm{~km}$ in depth, respectively. In contrast, uncertainties of absolute locations were large for events far away from our OBS stations, for example earthquakes along another three profiles (Fig. 6b). Because of the relatively large epicentral distances, outer-rise events generally had large location uncertainties (Figs 6 and S02).

\subsubsection{Neighbouring earthquakes}

Due to the insufficient number of clear impulsive $P$ and $S$ arrivals, a large number of detected events were not located. Here we used the well-located 1248 earthquakes as templates to search for 'repeating' or 'neighbouring' earthquakes according to their waveform similarity. Any earthquakes that had waveform cross-correlation coefficients larger than 0.8 on a single OBS were assigned with same locations of the templates. For example, waveforms of an earthquake (M2.6) located by Hypoinverse2000 exhibited impulsive arrivals on four OBSs, while waveforms of a detected, neighboring earthquake (M1.8) were only visible on PA03 station (Fig. 7). Earthquakes similar to the $M 1.8$ event could not be located by Hypoinverse2000, but were located by our neighboring earthquake approximation.

We then repeated the cross-correlation process between newly located, neighboring events and the remaining earthquakes from SCC detection. The cross-correlation process was stopped after 6 

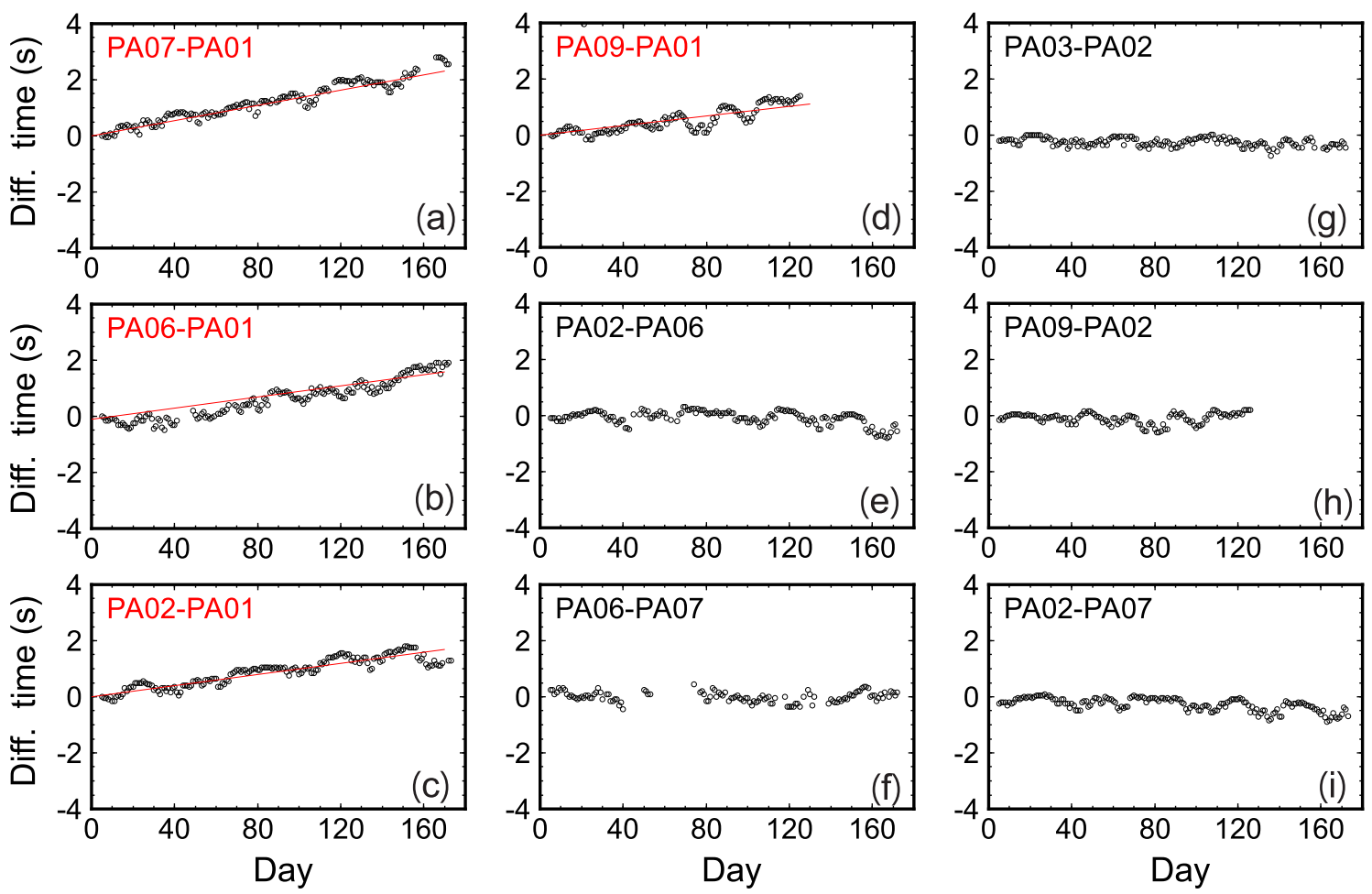

Figure 4. Temporal variation of relative clock errors between each OBS pair determined by the changes in the largest amplitude of the NCCF. (a-d) Obvious linear time drifting between PA01 and other OBSs. Red lines show the best-fitting linear trend. (e-i) Subtle time drifting among PA02, PA03, PA06, PA07 and PA09 OBSs.

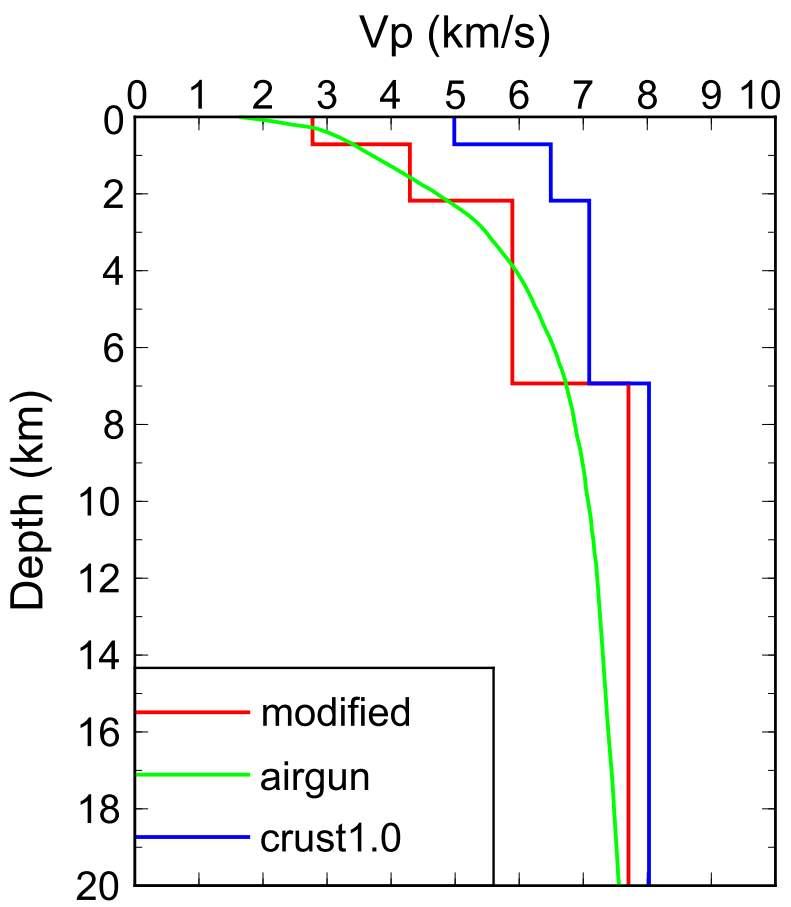

Figure 5. The blue line denotes the Crust 1.0 velocity model in the region. The green curve shows the average new $P$-wave velocity derived from multichannel seismic reflection experiment (Wan et al. 2019). The red is modified based on the two and is used in earthquake location.

iterations because of little new findings ( $<10$ events) in additional iteration. Finally, we found 756 additional neighbouring earthquakes and thus obtained locations of 2004 earthquakes in total (Table 2).
Table 1. Layered 1-D velocity model used in this study. The velocity corresponds to the value at the top of each layer.

\begin{tabular}{lcc}
\hline $\begin{array}{l}\text { Depth } \\
(\mathrm{km})\end{array}$ & $\begin{array}{c}V_{p} \\
\left(\mathrm{~km} \mathrm{~s}^{-1}\right)\end{array}$ & $\begin{array}{c}V_{s} \\
\left(\mathrm{~km} \mathrm{~s}^{-1}\right)\end{array}$ \\
\hline & & \\
0.00 & 2.98 & 1.70 \\
0.72 & 4.49 & 2.57 \\
2.18 & 6.09 & 3.48 \\
6.93 & 7.90 & 4.51 \\
77.5 & 8.05 & 4.49 \\
165 & 8.17 & 4.51 \\
210 & 8.30 & 4.52 \\
260 & 8.48 & 4.61 \\
310 & 8.67 & 4.70 \\
\hline
\end{tabular}

\subsubsection{Relative earthquake relocation (HypoDD)}

We further improved the locations using the double-difference relocation algorithm (HypoDD), which can effectively reduce location errors due to structural variations and an imperfect velocity model (Waldhauser \& Ellsworth 2000). We obtained accurate $P$ - and $S$ wave differential times between any two events at an individual station by waveform cross-correlation (Yang et al. 2009). In total we got $421172 P$ - and $481359 S$-wave differential time measurements. The minimum number of observations for each event pair was 3 . The maximum radius for clustering events was $10 \mathrm{~km}$, larger than those normally used for inland data (e.g. Yang et al. 2009), because the precision of our initial absolute locations was relatively low due to the station coverage. Therefore, events with a separation distance of no more than $10 \mathrm{~km}$ belong to a same cluster during the relocation process. 


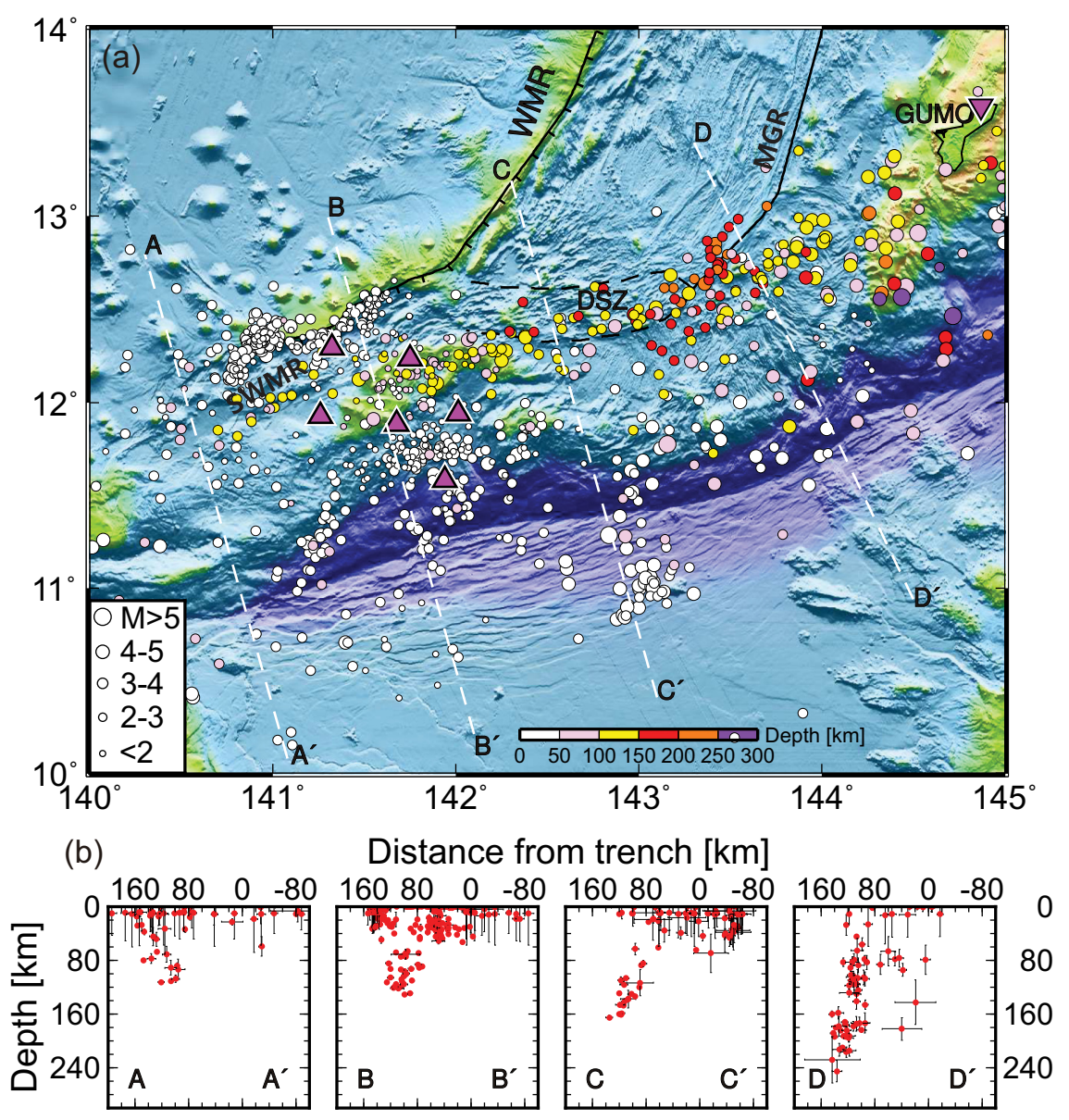

Figure 6. (a) Map of absolute earthquake locations (circles) coloured by depth based on the first OBS (triangles) observation in the southern Mariana subduction zone. (b) Cross-section view with a bin width of $30 \mathrm{~km}$ of seismicity (red dots) with locations shown panel (a). The horizontal and vertical black bars represent horizontal and vertical location uncertainties, respectively. Trench locations are marked as $0 \mathrm{~km}$.

Finally, 645 of the 2004 earthquakes were successfully relocated by HypoDD subject to the above prescribed requirements. The relocated earthquakes mainly distributed near the OBS locations and exhibited a few clusters, such as near the Southwest Mariana rift (SWMR). Most of them were shallow in depth, despite a few events extending to $180 \mathrm{~km}$ towards Guam. The average uncertainties of the HypoDD-located earthquakes were much reduced compared to the absolute locations, with horizontal uncertainty of $1.98 \mathrm{~km}$ and vertical one of $1.42 \mathrm{~km}$ (Fig. 8).

\section{RESULTS}

\subsection{Spatial distribution of seismicity}

A total of 7634 local earthquakes were detected in our 6-month deployment period of the OBS stations. Many detected events generated weak seismic signals on only one or two OBSs, and thus they were not well located. Eventually 2004 detected earthquakes were located, distributing over the outer-rise region, the slab, overriding plate and subduction interface (Fig. 9a). Within the subducting slab, a number of outer-rise earthquakes occurred in the Pacific Plate within $90 \mathrm{~km}$ from the trench axis. Most outer-rise earthquakes were shallower than $25 \mathrm{~km}$ in depth, except a few deeper than $50 \mathrm{~km}$ near the cross-sections AA' and CC' (Fig. 9). Although the shallow outer-rise earthquakes may be presumably normal faulting events, to delineate the extensional-compressional boundary within the incoming plate requires event focal mechanisms, which will be obtained in future work.

In contrast, we found a number of earthquakes at depths greater than $80 \mathrm{~km}$ and we interpreted these as slab earthquakes that can delineate the geometry of the subducting plate. As shown in Fig. 9(b), the subducting slab reaches $\sim 120 \mathrm{~km}$ in depth west of the Challenger Deep and extends to $\sim 240 \mathrm{~km}$ east of the Challenger Deep. Also, the dip angle of the slab increases from the west of the Challenger Deep to the east towards Guam at depths greater than $40 \mathrm{~km}$ (Fig. 9b). We noted two 'anomalous' earthquakes near the crosssection DD' that were located between $\sim 140$ and $190 \mathrm{~km}$ in depth. The two earthquakes did not generate clear waveforms at the GUMO station and thus were purely constrained by our OBS data. Because of the large hypocentral distance, their location uncertainties were large.

In the overriding plate, numerous earthquakes are concentrated along the northwest flank of the SWMR $\left(140.5-141.5^{\circ} \mathrm{E}, 12-13^{\circ} \mathrm{N}\right)$, within distances of $100-150 \mathrm{~km}$ perpendicular to the trench axis (Fig. 9). These earthquakes occurred at depths shallower than $50 \mathrm{~km}$. The northwest flank of the SWMR is clearly associated with seismicity at shallow depth, indicating the SWMR is undergoing active rifting. Between the SWMR and the trench, we also observed abundant shallow earthquakes $(<50 \mathrm{~km})$ near the OBS array, including that these events occurring on the subduction interface. Although few shallow earthquakes were located in the region far 


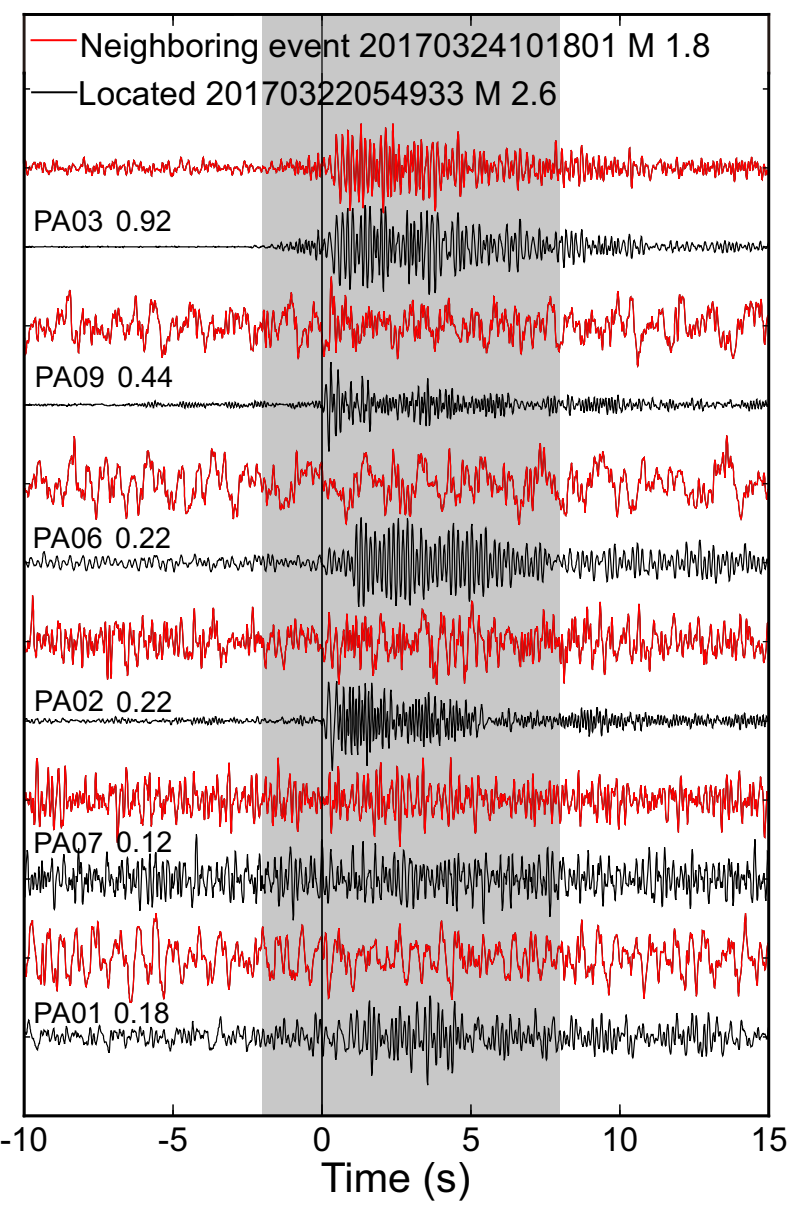

Figure 7. Waveforms of an earthquake located using Hypoinverse (black) and a detected, neighboring earthquake (red) aligned by $S$-wave arrivals. The grey shadow marks the time window $(2 \mathrm{~s}$ before and $8 \mathrm{~s}$ after the $S$ wave arrival) used for waveform cross-correlation. The station names and cross-correlation coefficients are marked on the left.

Table 2. Number of events analysed by different methods.

\begin{tabular}{llc}
\hline Analysis & Method & Number \\
\hline Earthquake identification & Matched filter & 7634 \\
Absolute location & Hypoinverse2000 1248 & 2004 \\
Relative location & Neighboring events 756 & \\
\hline
\end{tabular}

away from the OBS array, we did find a number of slab earthquakes of intermediate depths between our OBS array and the Guam Island (Fig. 9).

\subsection{Magnitude calibration}

We calibrated the magnitudes of all located earthquakes by measuring relative amplitudes to their nearest catalogue earthquakes on all OBSs using eq. (1). Typically, magnitudes of detected small events are estimated based on local magnitude (e.g. Yang et al. 2009). However, due to the lack of near-field stations in the southern Mariana, template earthquakes in the USGS catalogue only have body wave magnitude $\left(m_{b}\right)$. Therefore, our calibrated magnitudes were derived based on $m_{b}$ with amplitude-magnitude scaling $c=1$, although small local events were detected in a slightly higher frequency band than teleseismic body wave.
The magnitudes of all located earthquakes range from 1.1 to 5.6 (Fig. 10a). Apparently, our new catalogue contains a large number of small magnitude events that were missed in the USGS catalogue. Most of them occurred in the overriding plate close to our OBS network, including the SWMR segment. However, it was surprising that many moderate earthquakes were also missed in the USGS catalogue, including four $M>5$ earthquakes. An outer-rise M5.3 event did not cause any impulsive features at the GUMO station (Fig. 11), and thus was not reported by the USGS catalogue. However, other three $M>5$ events generated clear waveforms on the GUMO station, but still were not reported by the USGS catalogue.

For all located earthquakes, we compared the calibrated magnitude with their initial magnitude determined during the match filter detection. The difference in magnitude before and after calibration obeys a normal distribution, with a mean value of 0.22 and the standard deviation of 0.56 (Fig. 10c). Its 95 per cent confidence interval is between -0.88 and 1.32. Because the magnitude is determined in a relative sense based on waveform amplitude ratio, it is affected by the total number of available stations and the time window, which is related to the earthquake locations (e.g. Meng et al. 2018). Large magnitude differences $(>1)$ could result from changes in the chosen reference USGS events and using different waveform segments during earthquake detection and magnitude calibration.

\section{DISCUSSION}

Using the near-field recordings acquired in the first OBS experiment in the southern Mariana subduction zone, we constructed a comprehensive catalogue of earthquakes in the region between December 2016 and June 2017. Our significantly improved catalogue provides a valuable resource to study the spatial distribution of the events, and to understand the active fault system and subduction zone dynamics.

\subsection{Improvement of earthquake catalogue in the southern Mariana subduction zone}

The OBS array in the southernmost Mariana subduction zone enable us to significantly improve the local earthquake catalogue, including the magnitude of completeness and the level of seismic activity. Using 53 template earthquakes, we have successfully detected more than 7000 earthquakes during the 6-month deployment period, which is two order of magnitudes more than the USGS catalogue earthquakes. Such improvement in the recorded seismicity has not been found on land data, in which several to 10-fold increase is usually reported (Peng \& Zhao 2009; Yang et al. 2009; Lengliné et al. 2012; Meng et al. 2012). The stark contrast likely stems from a more complete land-based catalogue because of better station coverage and SNR. But it also highlights the significant deficiency of the USGS earthquake catalogue in the Mariana region.

Such deficiency in the Mariana earthquake catalogue is attributed to sparse seismic network and strong fluctuation of noise levels that may obscure the impulsive earthquake waveforms. This is reflected in our new catalogue that a number of earthquakes with magnitudes greater than 4 were not reported in the USGS catalogue, including four $M>5$ earthquakes. If the nearest GUMO station is noisy, these moderate earthquakes may not be reported, as shown in our example of one M5.3 earthquake (Fig. 11). This is why the earthquakes 

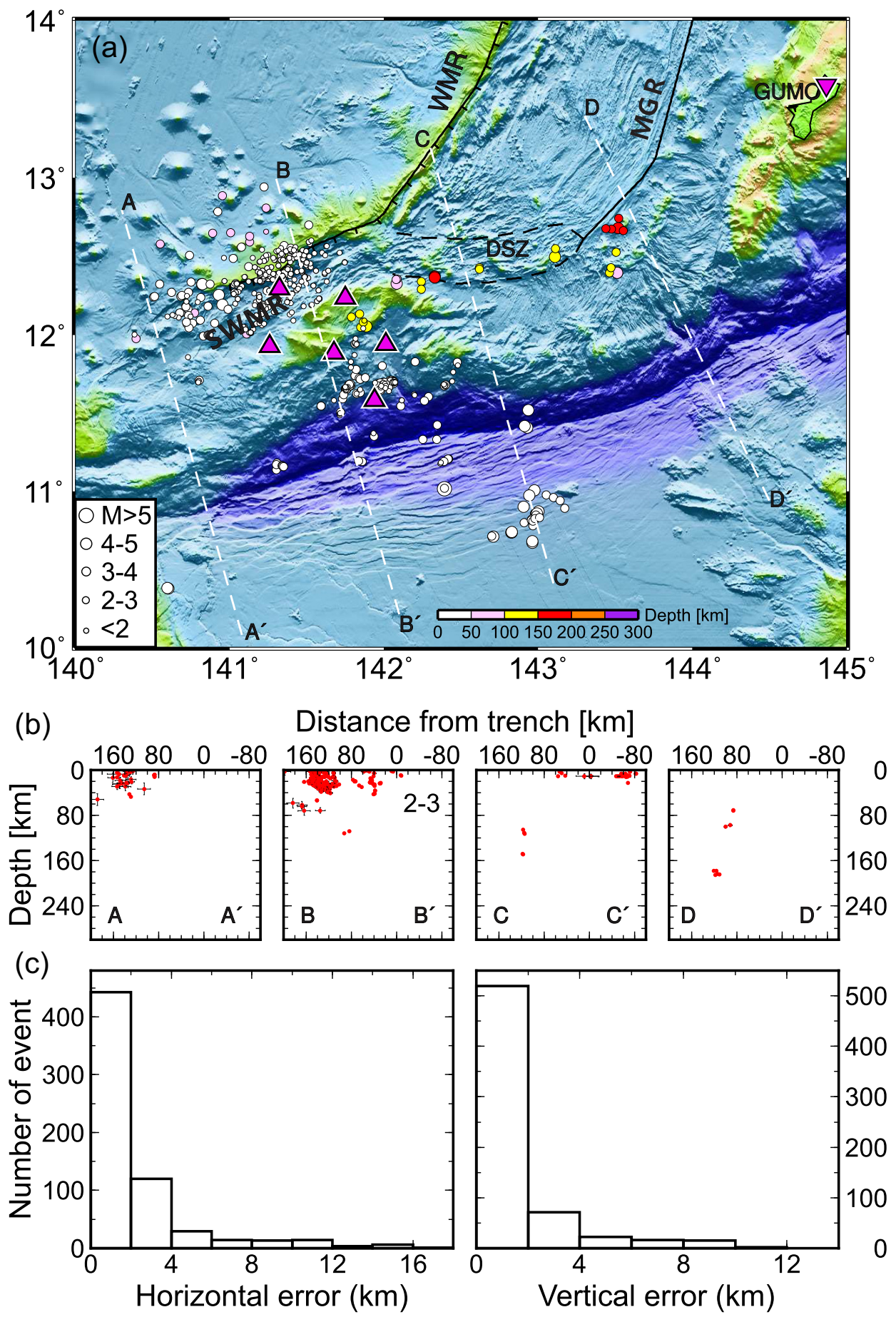

Figure 8. (a) Map of relative earthquake locations (circles) coloured by depth. (b) See Fig. 6(b) for more details for the legend. (c) Histogram distribution of horizontal and vertical relative location uncertainties.

in the USGS catalogue are limited to M4 during our OBS deployment period (Fig. 10b). Moreover, fluctuation of noise levels on our OBS recordings may limit our detection and location threshold. For instance, one M2.6 earthquake was located using recordings on four OBS stations. We then used this event to find 'repeating' or 'neighbouring' earthquakes and found one earthquake that had nearly identical waveforms on the PA03 OBS but was not located by Hypoinverse or HypoDD (Fig. 7). The magnitude of this event was 1.8, which did not generate clear impulsive signals on other OBSs due to the strong noise. Thus we can also increase the number of located earthquakes by finding such 'repeating' or 'neighbouring' events that were not initially located due to the insufficient clear arrivals.

Our template catalogue is from the USGS and thus our estimated magnitudes of the detected earthquakes are relative to the USGS magnitudes. Although most earthquake magnitudes are generally consistent among different catalogues, for example the USGS and China network catalogue (Bormann et al. 2007), magnitudes of Mariana earthquakes may differ significantly from one catalogue to another. For instance, the $m_{b}$ are systematically greater in the 

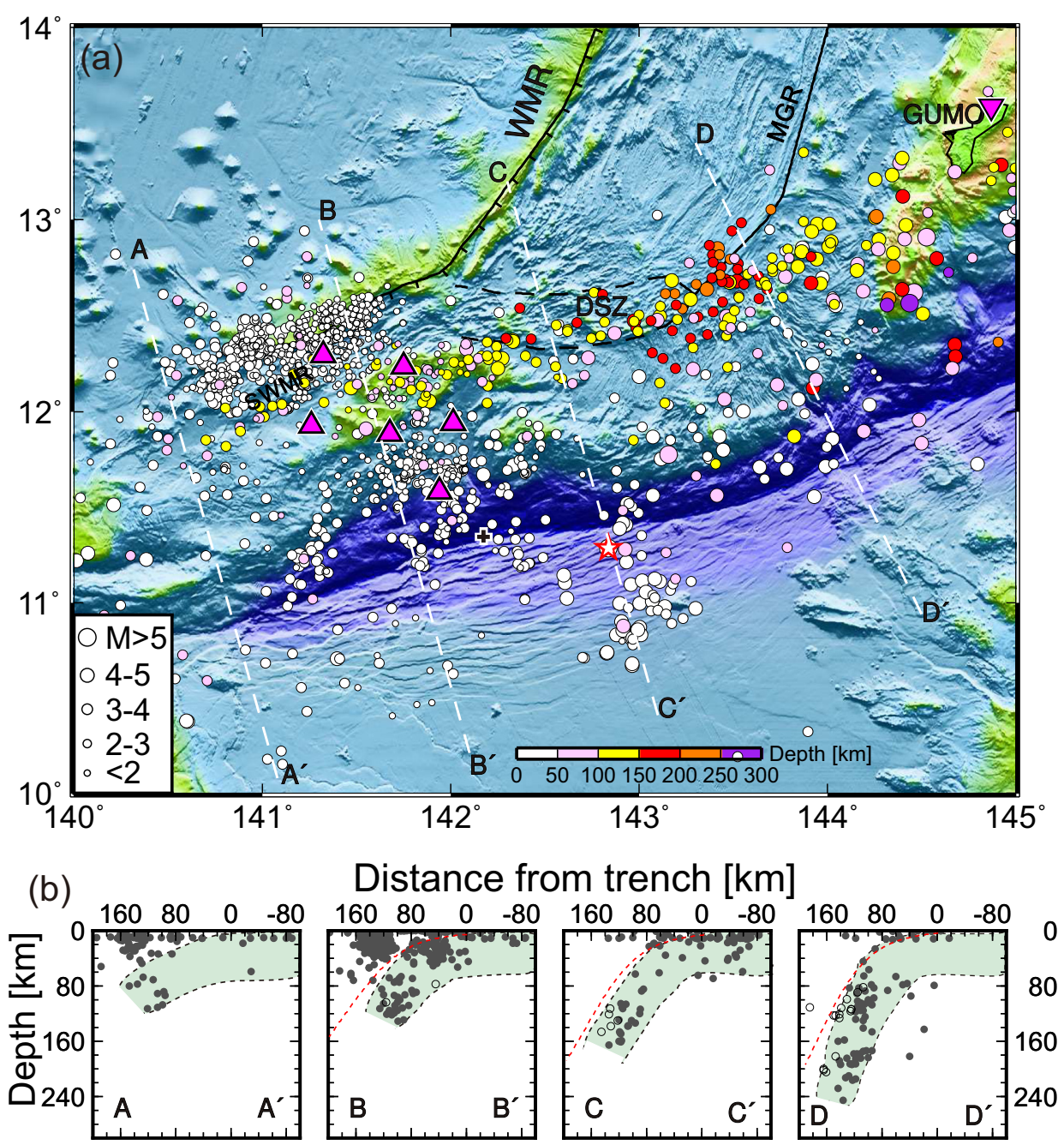

Figure 9. (a) Map of all located earthquakes (circles). The star marks an earthquake whose waveforms are shown in Fig. 11. (b) Cross-section view with a bin width of $30 \mathrm{~km}$ of seismicity (grey circles) with locations shown panel (a). Open dots represent historical earthquakes with depth greater than $70 \mathrm{~km}$ in the USGS catalogue since 1900. The shapes of the green slabs come from the located seismicity. The red dashed lines show the slab traces according to the Slab2.0 model (Hayes et al. 2018).

USGS catalogue than those in the International Data Center (IDC) catalogue (Murphy \& Barker 2003), probably due to differences in seismograph response, calibration functions and different time window for measurement of maximum $P$-wave amplitudes (Murphy \& Barker 2003; Bormann et al. 2007). In fact, the magnitude differences are especially significant in the southern Mariana, with the IDC values being lower by an average of 0.5 magnitude units (Fig. S1), with large scattering from -1.6 to 0.8 .

\section{$6.2 b$ Value}

We also calculated the $b$ value using our newly acquired catalogue. The magnitude and frequency distribution of our located earthquakes show that the magnitude becomes incomplete below 1.8, which was calculated using the software ZMAP (Wiemer 2001; Fig. 10b). Therefore, we performed linear regression to derive the $b$ value only for magnitudes larger than 1.8 . The best-fitting $b$ value is $0.76 \pm 0.03$, lower than the $b$ value of $\sim 1.3$ reported using the Advanced National Seismic System (ANSS) earthquake catalogue in a much longer time window (Nishikawa \& Ide 2014). Because of our network coverage, we may have omitted locations of small earthquakes that were far from the OBS stations, which could lead to underestimation of the $b$ value.

In addition, the $b$ value may be affected by the scaling factor $c$ when we calibrated the magnitudes of our located earthquakes. Because our template earthquakes have body wave magnitudes that were derived from logarithmic value of $P$-wave amplitude, we simply took $c=1$. Indeed, the amplitude-magnitude scaling $c$ values might be more complicated (Shelly et al. 2016). Although many studies using local magnitudes $\left(M_{\mathrm{L}}\right)$ adopted $c=1$ (e.g. Yang et al. 2009; Benz et al. 2015), it is suggested that $c$ should reflect the ratio of seismic moments for the frequency band of $2-15 \mathrm{~Hz}$, which is 2/3 (Hanks \& Kanamori 1979; Shelly et al. 2016). In order to reduce such bias caused by $c$, recent studies calibrate $c$ value by performing linear fit between the magnitude differences and amplitude ratios for a large number of template earthquakes, obtaining $c=0.787$ (Shelly et al. 2016) and $c=0.788$ (Meng et al. 2018), respectively. However, due to the small number of our template earthquakes, we could not examine $c$ following the procedure of Shelly et al. (2016). Future studies using more OBS stations and longer deployment period would continue to improve the $b$ value evaluation. 


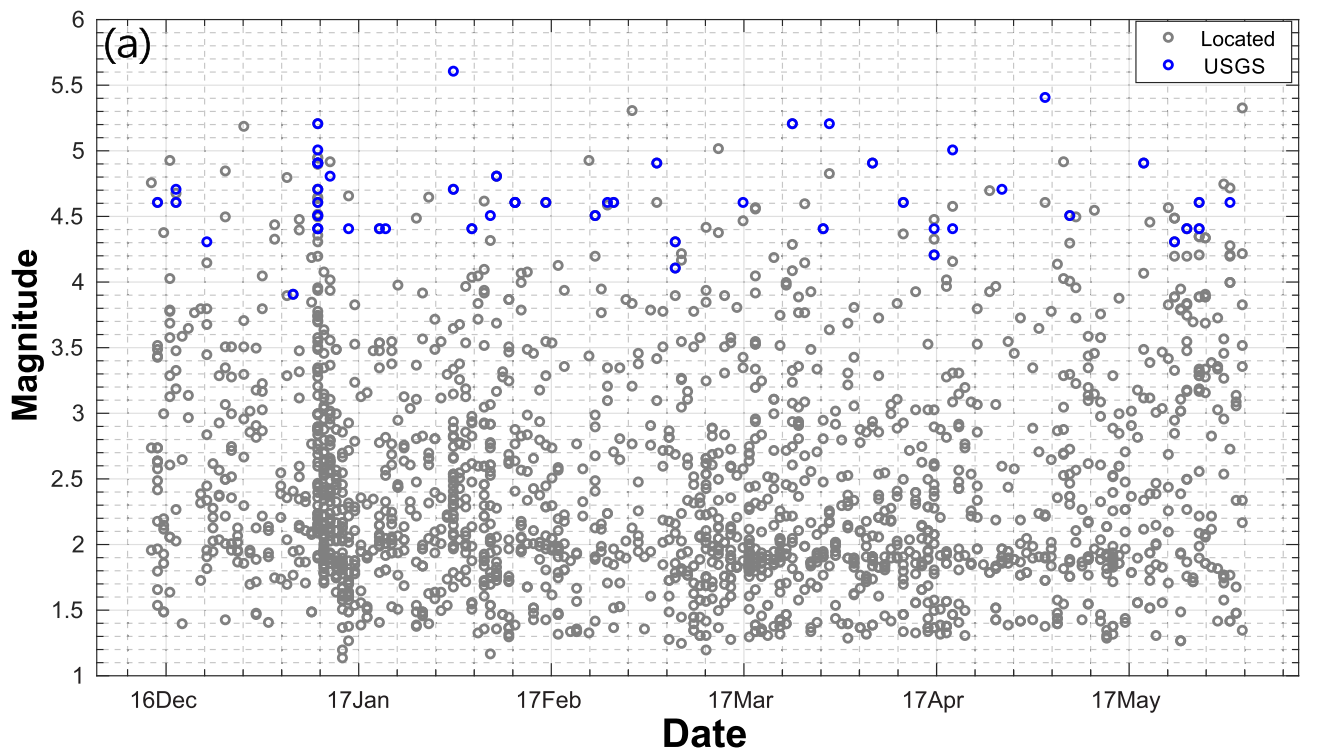

(b)

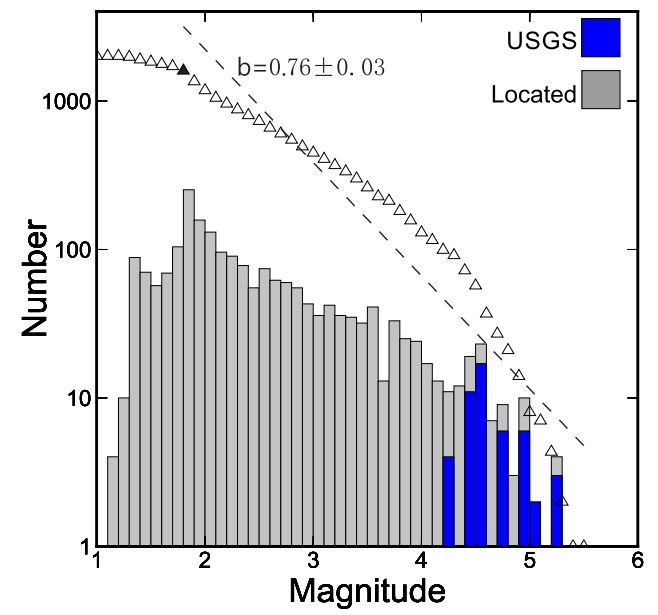

(c)

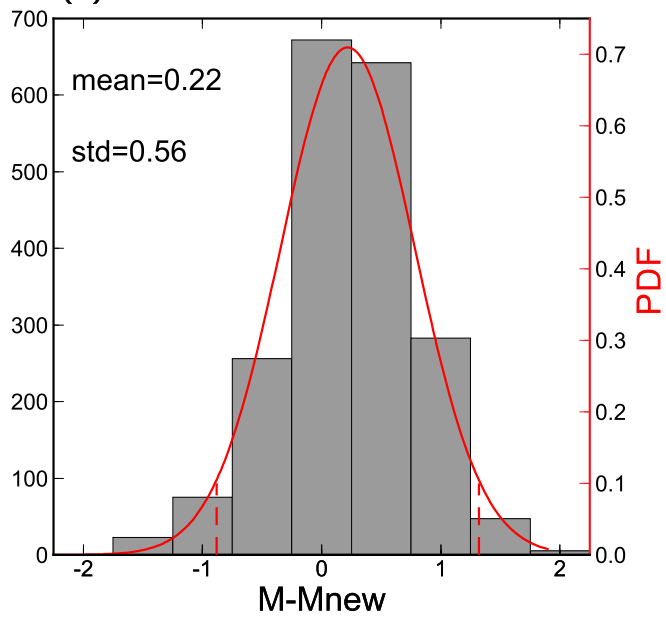

Figure 10. (a) Magnitudes and occurrence times of earthquakes in our new (grey) and the USGS (blue) catalogs. (b) Frequency-magnitude distribution. Blue (USGS) and grey (this study) histograms show the number of earthquakes in each bin (width of 0.1). Black triangles represent cumulative number of earthquakes. The black dashed line shows the optimal least-square fit for earthquakes larger than $M 1.8$. (c) Difference before (M) and after (Mnew) magnitude calibration. The solid red curve shows the normal probability density function (PDF) of magnitude difference with the 95 per cent confidence interval ( -0.88 , 1.32) marked by the two red dashed lines.

\subsection{Constraints on the subducting slab geometry and plate deformation}

A fundamental issue in subduction zones is the slab geometry, which could be delineated by seismicity (Katsumata \& Sykes 1969; Samowitz \& Forsyth 1981; Nakamura et al. 1998; Peacock 2001). However, location uncertainties of historical earthquakes in the Mariana region are quite large, which may hinder the more accurate determination of the position and geometry of the slab (Shiobara et al. 2010; Emry et al. 2011). Our new catalogue based on the near-field OBS recordings can now provide improved constraints on the subducting slab. We can clearly identify slab-related earthquakes according to the distribution of earthquakes, delineating the subducting slab in the southern Mariana subduction zone (Fig. 9b). The Wadati-Benioff zone (WBZ) of the southern Mariana varies significantly along the trench. It terminates at $\sim 100 \mathrm{~km}$ depth in the west near the cross section $\mathrm{AA}^{\prime}$, gradually extends to greater depths toward Guam, and reaches at depth of $\sim 240 \mathrm{~km}$ near the cross section DD' (Fig. 9b). The average dip angle increases from $\sim 30^{\circ}$ to $\sim 60^{\circ}$ eastward at depth greater than $30 \mathrm{~km}$, which is slightly steeper than the Slab2.0 model (Hayes et al. 2018) at the same depth (Figs $9 \mathrm{~b}$ and S04). In comparison, our results are consistent with the Slab2.0 model at depth shallower than $30 \mathrm{~km}$, yielding an average dip angle of $\sim 18^{\circ}$.

The present-day geometry of subducting slab is significantly different between the southern and central Mariana. Beneath the central Mariana trench, earthquakes extend to $\sim 600 \mathrm{~km}$ depth, reflecting a $\sim 1300$-km-long WBZ with a nearly vertical dip angle at greater depths (Gudmundsson \& Sambridge 1998; Fryer et al. 2003; Gvirtzman \& Stern 2004; Miller et al. 2006), suggesting that the slab is anchored in the lower mantle (Van der Hilst \& Seno 1993; Gvirtzman \& Stern 2004). According to earthquake locations in the USGS earthquake catalogue, the slab bends remarkably at depth of $100-200 \mathrm{~km}$ that separates a nearly vertical lower portion from a shallow-dipping upper segment $\left(\sim 16^{\circ}-17^{\circ}\right.$ at depth of $50-100 \mathrm{~km}$, Gvirtzman \& Stern 2004). In comparison, the WBZ beneath the 


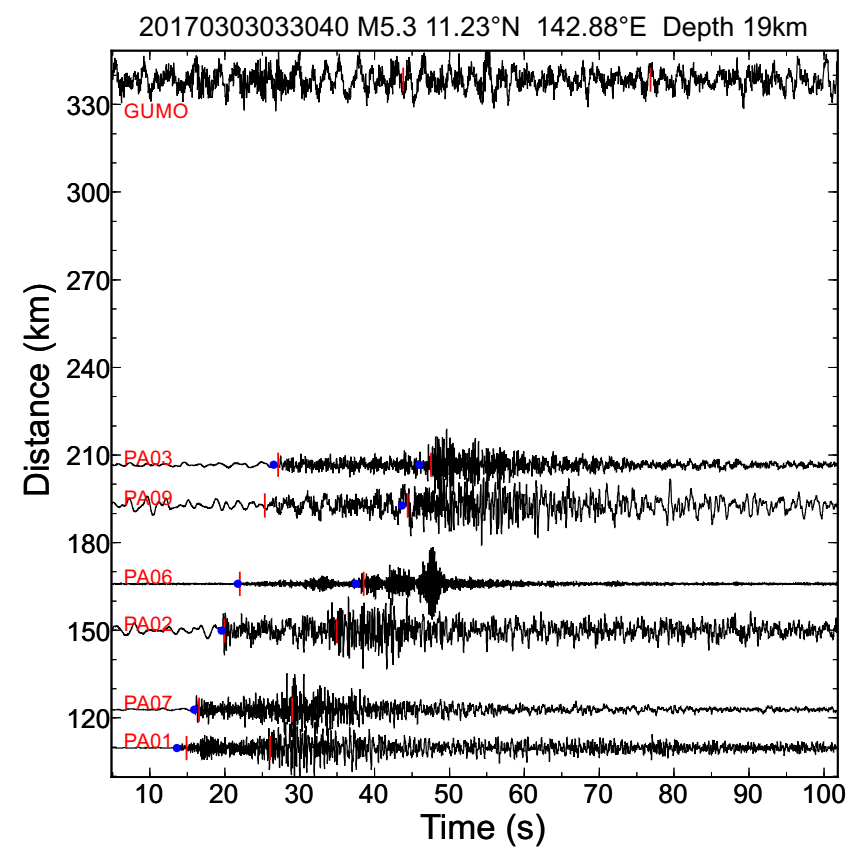

Figure 11. Waveforms of a M5.3 earthquake (location shown as the red star in Fig. 9a) that is missed in the USGS catalogue due to a lack of impulsive arrivals at GUMO. Red bars and blue dots indicate the theoretical and handpicked arrival times of $P$ and $S$ waves, respectively.

southernmost Mariana is only traced by earthquakes to depths of $\sim 100-240 \mathrm{~km}$, consistent with the tomographic results that indicated a short slab ( $\sim 250 \mathrm{~km}$ in length) south of the Guam Island (Miller et al. 2006).

The improved constraints on the slab geometry are important for understanding dynamics of slab and upper plate in the southern Mariana. Smaller slab dip angles usually correlate with compression in continental advancing upper plates, whereas large dip angles are often associated with extension in oceanic retreating upper plates (Ruff \& Kanamori 1980; Lallemand et al. 2005). It has been suggested that active backarc spreading is associated with dips larger than $50^{\circ}$ (Lallemand et al. 2005). Based on southwardly narrowing of the forearc and steepening slab at depth of 50-100-km along the Mariana, Gvirtzman \& Stern (2004) hypothesized that the width of interplate coupling zone decreased southward. Our results confirm a steeper slab in the south $\left(\sim 35^{\circ}-45^{\circ}\right)$ than in the central Mariana $\left(\sim 16^{\circ}-17^{\circ}\right)$ at middle depth range $(50-100 \mathrm{~km})$, and thus indicate less compressional stress state in the forearc and decreasing width of plate coupling zone and/or coupling degree.

Furthermore, the increasing dip angle from west to east ( $\mathrm{AA}^{\prime}-$ $D^{\prime}$ ) implies potential slab tear, which was proposed near Guam although the exact locations were in debate (Gvirtzman \& Stern 2004; Miller et al. 2006). Gvirtzman \& Stern (2004) proposed a north-south trending slab tear south of the Guam Island, while Miller et al. (2006) suggested an east-west tearing north of Guam based on tomographic images and seismicity. Because of our OBS coverage, we cannot resolve the slab structure beneath Guam. However, our new local earthquake data can provide critical constraints on flexural bending of the subducting plate, as done by 2-D models at the southern Mariana (e.g. Zhang et al. 2014, 2018; Zhou et al. 2015; Zhou \& Lin 2018). As shown in a recent 3-D model (Zhang et al. 2018), slab tearing can be inferred by quantifying non-elastic deformation. Such 3-D modelling will be conducted to investigate the location of slab tear in the southern Mariana with constraints from our seismicity locations.

The observed short subducting slab, which is not anchored by the resistance of lower mantle, may be a favorable factor triggering rapid slab steepening (or rollback) in the southernmost Mariana. With an old plate age (large density) in the Mariana trench, the slab can sink due to the negative buoyancy from the mantle without resistance from the lower mantle (Stern et al. 2003; Gvirtzman \& Stern 2004). In addition, proximity to the lateral slab edge may also promote slab rollback by facilitating return flow around the edge (Gvirtzman \& Stern 2004; Schellart et al. 2007). The slab rollback in the southern Mariana has already been revealed by two evidences: the southwardly increasing opening rate of the Mariana Trough (Kato et al. 2003) and the numerous normal faults in the forearc west of the Guam Island (Martinez \& Baker 2000; Miller et al. 2006; Martinez et al. 2018). However, one may argue that the slab should be steeper westward in the southern Mariana, if a short slab favors slab rollback. We suggest that increasing length of slab is a positive factor controlling the slab rollback in the southern Mariana, where the slab is not anchored by the lower mantle. Increase in slab length could facilitate slab rollback until the slab tip approaches the transition zone (Schellart 2004). Therefore, it is reasonable that the slab of greater length is steeper in the eastern side, while it is shallower with a shorter length in the western side. Moreover, the interpretation of controls on slab rollback may be rather complex, because rollback velocity is related to many factors, such as the subducting slab age, density, thickness, lithospheric strength, viscosity, the overriding plate motion and rheological strength (Capitanio et al. 2010; Yang et al. 2017, 2018).

Future studies on focal mechanisms of earthquakes and seismic tomography can provide more evidences on local stress field and subduction zone dynamics. Such studies have been conducted in the central Mariana. For example, the shallow megathrust defined by shallowly dipping thrust earthquakes, shows an average dip of only $21^{\circ}$ at depth of 20-60 km and a seismogenic zone width of $\sim 100 \mathrm{~km}$ (Emry et al. 2011), contradicting the views of steep slab and a narrow seismogenic width (Pacheco et al. 1993; Hyndman et al. 1997). The downdip seismogenic width has been suggested to play critical roles in along-strike rupture extent and thus future earthquake magnitude (Weng \& Yang 2017). Moreover, seismic tomography based on the well-constrained local seismicity is effective to constrain mantle wedge processes associated with subduction, such as serpentinization of mantle wedge and forearc (Barklage et al. 2015). These studies will be conducted using our OBS data from the southern Mariana after we correct the polarities of waveforms of the horizontal components.

\section{CONCLUSIONS}

We conducted the first OBS experiment near the Challenger Deep from December 2016 to June 2017 and acquired the first local OBS data set in the region. After correcting the instrumental time drifting, we performed matched filter detection and earthquake location and constructed a comprehensive catalogue of local earthquakes. Using the only 53 available earthquakes of the USGS catalogue as template, we found more than 7600 local earthquakes in the 6month deployment period of our OBS stations and located $>2000$ of events with relatively high resolution. The northwest flank of the SWMR is clearly associated with seismicity at shallow depth, indicating that the SWMR is undergoing active rifting. According 
to the location results, the maximum hypocentral depths of slabrelated earthquakes vary significantly along strike, increasing from $\sim 100 \mathrm{~km}$ in the west to $\sim 240 \mathrm{~km}$ in the east towards Guam. The slab dip angle also increases from the Challenger Deep towards Guam. Comparing with the central Mariana, seismicity outlines a relatively short downdip length of the subducting slab in the southern Mariana, which plays an important role in controlling the subduction dynamics of the southern segment.

\section{ACKNOWLEDGEMENTS}

We express our appreciation to the science parties and crew members of the R/V Shiyan 3 for deployment and collection of the OBS instruments during the Mariana expeditions. This study is supported by the Hong Kong Research Grant Council Grants (No. 14313816), Faculty of Science at CUHK, Chinese Academy of Sciences (No. Y4SL021001, QYZDY-SSW-DQC005, 133244KYSB20180029), the National Natural Science Foundation of China (No. 41890813, 91628301, 41676042, U1701641, 41576041, 91858207 and U1606401), the National Key R\&D Program of China (2018YFC0309800 and 2018YFC0310100). Generic Mapping Tools (Wessel \& Smith 1991) and PSSAC (developed by Prof Lupei Zhu) are used for data analysis and figure preparation in this study. Constructive comments from Dr Lidong Bie and two anonymous reviewers are helpful in improving the manuscript.

\section{REFER E N CES}

Barklage, M., Wiens, D.A., Conder, J.A., Pozgay, S., Shiobara, H. \& Sugioka, H., 2015. P and S velocity tomography of the Mariana subduction system from a combined land-sea seismic deployment, Geochem. Geophys. Geosyst., 16(3), 681-704.

Bensen, G.D., Ritzwoller, M.H., Barmin, M.P., Levshin, A.L., Lin, F., Moschetti, M.P., Shapiro, N.M. \& Yang, Y., 2007. Processing seismic ambient noise data to obtain reliable broad-band surface wave dispersion measurements, Geophys. J. Int., 169(3), 1239-1260.

Benz, H.M., McMahon, N.D., Aster, R.C., McNamara, D.E. \& Harris, D.B., 2015. Hundreds of earthquakes per day: the 2014 Guthrie, Oklahoma, earthquake sequence, Seismol. Res. Lett., 86(5), 1318-1325.

Bormann, P., Liu, R., Ren, X., Gutdeutsch, R., Kaiser, D. \& Castellaro, S., 2007. Chinese National Network Magnitudes, their relation to NEIC magnitudes, and recommendations for new IASPEI magnitude standards, Bull. seism. Soc. Am., 97(1B), 114-127.

Cai, C., Wiens, D.A., Shen, W. \& Eimer, M., 2018. Water input into the Mariana subduction zone estimated from ocean-bottom seismic data, Nature, $\mathbf{5 6 3}, 389-392$.

Capitanio, F.A., Stegman, D.R., Moresi, L.N. \& Sharples, W., 2010. Upper plate controls on deep subduction, trench migrations and deformations at convergent margins, Tectonophysics, 483(1-2), 80-92.

Ekström, G., Nettles, M. \& Dziewoński, A.M., 2012. The global CMT project 2004-2010: centroid-moment tensors for 13,017 earthquakes, Phys. Earth planet. Inter., 200-201, 1-9.

Emry, E.L., Wiens, D.A. \& Daniel, G.C., 2014. Faulting within the Pacific plate at the Mariana Trench: implications for plate interface coupling and subduction of hydrous minerals, J. geophys. Res.: Solid Earth, 119(4), 3076-3095.

Emry, E.L., Wiens, D.A., Shiobara, H. \& Sugioka, H., 2011. Seismogenic characteristics of the Northern Mariana shallow thrust zone from local array data, Geochem. Geophys. Geosyst., 12(12), Q12008, doi: 10.1029/2011GC003853.

Fryer, P., Becker, N., Appelgate, B., Martinez, F., Edwards, M. \& Fryer, G., 2003. Why is the challenger deep so deep? Earth planet. Sci. Lett., 211(3-4), 259-269.

Gouédard, P., Seher, T., McGuire, J.J., Collins, J.A. \& van der Hilst, R.D., 2014. Correction of ocean-bottom seismometer instrumental clock errors using ambient seismic noisecorrection of ocean-bottom seismometer instrumental clock errors using ambient seismic noise, Bull. seism. Soc. Am., 104(3), 1276-1288.

Gribble, R.F., Stern, R.J., Bloomer, S.H., Stüben, D., O’Hearn, T. \& Newman, S., 1996. MORB mantle and subduction components interact to generate basalts in the southern Mariana Trough back-arc basin, Geochim. Cosmochim. Acta., 60(12), 2153-2166.

Gudmundsson, Ó. \& Sambridge, M., 1998. A regionalized upper mantle (RUM) seismic model, J. geophys. Res.: Solid Earth, 103(B4), 71217136.

Gvirtzman, Z. \& Stern, R.J., 2004. Bathymetry of Mariana trench-arc system and formation of the Challenger Deep as a consequence of weak plate coupling, Tectonics, 23(2), TC2011, doi:10.1029/2003TC001581.

Hanks, T.C. \& Kanamori, H., 1979. A moment magnitude scale, J. geophys. Res.: Solid Earth, 84(B5), 2348-2350.

Hayes, G.P., Moore, G.L., Portner, D.E., Hearne, M., Flamme, H., Furtney, M. \& Smoczyk, G.M., 2018. Slab2, a comprehensive subduction zone geometry model, Science, 362, 58-61.

Hyndman, R.D., , Yamano, M. \& Oleskevich, D.A., 1997. The seismogenic zone of subduction thrust faults, Island Arc, 6, 3(8):244-260.

Kato, T., Beavan, J., Matsushima, T., Kotake, Y., Camacho, J.T. \& Nakao, S., 2003. Geodetic evidence of back-arc spreading in the Mariana Trough, Geophys. Res. Lett., 30(12), 1625.

Katsumata, M. \& Sykes, L.R., 1969. Seismicity and tectonics of the western Pacific: Izu-Mariana-Caroline and Ryukyu-Taiwan regions, J. geophys. Res., 74(25), 5923-5948.

Kennett, B.L.N., Engdahl, E.R. \& Buland, R., 1995. Constraints on seismic velocities in the Earth from traveltimes, Geophys. J. Int., 122(1), 108-124.

Klein, F.W., 2002. User's guide to HYPOINVERSE-2000, a Fortran program to solve for earthquake locations and magnitudes, Open-File Report, pp. 123.

Lallemand, S., Heuret, A. \& Boutelier, D., 2005. On the relationships between slab dip, back-arc stress, upper plate absolute motion, and crustal nature in subduction zones, Geochem. Geophys. Geosyst., 6(9), Q09006.

Laske, G., Masters, G. \& Ma, Z., 2013. Update on CRUST1. 0 - a 1-degree global model of Earth's crust,in Geophysical Research Abstracts. EGU General Assembly, European Geophysical Union, EGU2013-2658.

Le, B.M., Yang, T., Chen, Y.J. \& Yao, H., 2018. Correction of OBS clock errors using Scholte waves retrieved from cross-correlating hydrophone recordings, Geophys. J. Int., 212(2), 891-899.

Lengliné, O., Enescu, B., Peng, Z. \& Shiomi, K., 2012. Decay and expansion of the early aftershock activity following the 2011, Mw9.0 Tohoku earthquake, Geophys. Res. Lett., 39(18), L18309, doi:10.1029/2012GL052797.

Lin, J., Sun, J., Xu, M., Zeng, X. \& Zhou, Z., Science Party of R/V Shiyan 3, 2017. Seismic Experiments Investigating Plate Dynamics of the Challenger Deep Region in Southern Mariana Trench. AGU Fall Meeting.

Li, P., Tao, J., Lin, J., He, C., Shi, Q., Li, X. \& Zhang, C., 2019. Stratification of dissolved organic matter in the upper $2000 \mathrm{~m}$ water column at the Mariana Trench, Sci. Total Environ., 668, 1222-1231.

Martinez, F. \& Baker, N.A., 2000. Geophysical characteristics of the southern Mariana Trough, $11^{\circ} 50^{\prime} \mathrm{N}-13^{\circ} 40^{\prime} \mathrm{N}, J$. geophys. Res.: Solid Earth, 105(B7), 16591-16607.

Martinez, F., Stern, R.J., Kelley, K.A., Ohara, Y., Sleeper, J.D., Ribeiro, J.M. \& Brounce, M., 2018. Diffuse extension of the Southern Mariana margin, J. geophys. Res.: Solid Earth, 123(1), 892-916.

Meng, X., Yang, H. \& Peng, Z., 2018. Foreshocks, $b$ value map, and aftershocktriggering for the $2011 \mathrm{Mw} 5.7$ Virginia earthquake. J. geophys. Res.: Solid Earth, 123(6), 5082-5098.

Meng, X., Yu, X., Peng, Z. \& Hong, B., 2012. Detecting earthquakes around Salton Sea following the 2010 Mw7.2 El Mayor-Cucapah earthquake using GPU parallel computing, Proc. Comput. Sci., 9, 937-946.

Miller, M.S., Gorbatov, A. \& Kennett, B.L.N., 2006. Three-dimensional visualization of a near-vertical slab tear beneath the southern Mariana arc, Geochem. Geophys. Geosyst., 7(6), Q06012, doi:10.1029/2005GC001110.

Murphy, J.R. \& Barker, B.W., 2003. Revised distance and depth corrections for use in the estimation of short-period P-wave magnitudes, Bull. seism. Soc. Am., 93(4), 1746-1764. 
Nakamura, M., Ando, M. \& Ohkura, T., 1998. Fine structure of deep WadatiBenioff zone in the Izu-Bonin region estimated from S-to-P converted phase, Phys. Earth planet. Inter., 106(1-2), 63-74.

Nishikawa, T. \& Ide, S., 2014. Earthquake size distribution in subduction zones linked to slab buoyancy, Nat. Geosci., 7, 904-908.

Pacheco, J.F., Sykes, L.R. \& Scholz, C.H., 1993. Nature of seismic coupling along simple plate boundaries of the subduction type, J. geophys. Res.: Solid Earth, 98(B8), 14133-14159, doi:10.1029/93JB00349.

Peacock, S.M., 2001. Are the lower planes of double seismic zones caused by serpentine dehydration in subducting oceanic mantle? Geology, 29(4), 299-302.

Peng, Z. \& Zhao, P., 2009. Migration of early aftershocks following the 2004 Parkfield earthquake, Nat. Geosci., 2, 877-881.

Pyle, M.L., Wiens, D.A., Weeraratne, D.S., Shore, P.J., Shiobara, H. \& Sugioka, H., 2010. Shear velocity structure of the Mariana mantle wedge from Rayleigh wave phase velocities, J. geophys. Res.: Solid Earth, 115(B11), B11304, doi:10.1029/2009JB006976.

Ruff, L. \& Kanamori, H., 1980. Seismicity and the subduction process, Phys. Earth planet. Inter, 23(3), 240-252.

Samowitz, I.R. \& Forsyth, D.W., 1981. Double seismic zone beneath the Mariana Island Arc, J. geophys. Res.: Solid Earth, 86(B8), 7013-7021.

Schellart, W.P., 2004. Quantifying the net slab pull force as a driving mechanism for plate tectonics, Geophys. Res. Lett., 31(7), L07611, doi:10.1029/2004GL019528.

Schellart, W.P., Freeman, J., Stegman, D.R., Moresi, L. \& May, D., 2007. Evolution and diversity of subduction zones controlled by slab width, Nature, 446, 308.

Scholz, C.H. \& Campos, J., 1995. On the mechanism of seismic decoupling and back arc spreading at subduction zones, J. geophys. Res.: Solid Earth, 100(B11), 22103-22115.

Scholz, C.H. \& Campos, J., 2012. The seismic coupling of subduction zones revisited, J. geophys. Res.: Solid Earth, 117(B5), B05310, doi:10.1029/2011JB009003.

Shapiro, N.M., Campillo, M., Stehly, L. \& Ritzwoller, M.H., 2005. Highresolution surface-wave tomography from ambient seismic noise, Science, 307, 1615-1618.

Shelly, D.R., Ellsworth, W.L. \& Hill, D.P., 2016. Fluid-faulting evolution in high definition: connecting fault structure and frequency-magnitude variations during the 2014 Long Valley Caldera, California, earthquake swarm, J. geophysi. Res.: Solid Earth, 121(3), 1776-1795.

Shiobara, H., Sugioka, H., Mochizuki, K., Oki, S., Kanazawa, T., Fukao, Y. \& Suyehiro, K., 2010. Double seismic zone in the North Mariana region revealed by long-term ocean bottom array observation, Geophys. J. Int., 183(3), 1455-1469.

Stehly, L., Campillo, M. \& Shapiro, N.M., 2007. Traveltime measurements from noise correlation: stability and detection of instrumental time-shifts, Geophys. J. Int., 171(1), 223-230.

Stern, R.J., Fouch, M.J. \& Klemperer, S.L., 2003. An overview of the IzuBonin-Mariana subduction factory inside the subduction factory, Geophys. Monogr., Am. Geophys. Un., 138, 175-222

Van der Hilst, R. \& Seno, T., 1993. Effects of relative plate motion on the deep structure and penetration depth of slabs below the Izu-Bonin and Mariana island arcs, Earth planet. Sci. Lett., 120(3-4), 395-407.

Waldhauser, F. \& Ellsworth, W.L., 2000. A double-difference earthquake location algorithm: method and application to the Northern Hayward Fault, California, Bull. seism. Soc. Am., 90(6), 1353-1368.

Wan, K. et al., 2019, Deep seismic structure across the southernmost mariana trench: implications for arc rifting and plate hydration, J. geophys. Res.: Solid Earth, 124, doi:10.1029/2018JB0170800.
Weng, H. \& Yang, H., 2017. Seismogenic width controls aspect ratios of earthquake ruptures, Geophys. Res. Lett., 44(6), 2725-2732.

Wessel, P. \& Smith, W.H.F., 1991. Free software helps map and display data, EOS, Trans. Am. Geophys. Un., 72(41), 441-446.

Wiemer, S., 2001. A software package to analyze seismicity: ZMAP. Seismol. Res. Lett., 72(3), 373-382.

Yang, H., Zhu, L. \& Chu, R., 2009. Fault-plane determination of the 18 April 2008 Mount Carmel, Illinois, earthquake by detecting and relocating aftershocks, Bull. seism. Soc. Am., 99(6), 3413-3420.

Yang, T., Gurnis, M. \& Zhan, Z., 2017. Trench motion-controlled slab morphology and stress variations: implications for the isolated 2015 Bonin Islands deep earthquake, Geophys. Res. Lett., 44(13), 6641-6650.

Yang, T., Moresi, L., Zhao, D., Sandiford, D. \& Whittaker, J., 2018. Cenozoic lithospheric deformation in Northeast Asia and the rapidly-aging Pacific Plate, Earth planet. Sci. Lett., 492, 1-11.

Yao, H., van Der Hilst, R.D. \& de Hoop, M.V., 2006. Surface-wave array tomography in SE Tibet from ambient seismic noise and two-station analysis - I. Phase velocity maps, Geophys. J. Int., 166(2), 732-744.

Zhang, F., Lin, J. \& Zhan, W., 2014. Variations in oceanic plate bending along the Mariana trench, Earth planet. Sci. Lett., 401, 206-214.

Zhang, F., Lin, J., Zhou, Z., Yang, H. \& Zhan, W., 2018. Intra- and intertrench variations in flexural bending of the Manila, Mariana and global trenches: implications on plate weakening in controlling trench dynamics, Geophys. J. Int., 212(2), 1419-1449.

Zhang, J., Sun, Z., Xu, M., Yang, H., Zhang, Y. \& Li, F., 2018. Lithospheric 3-D flexural modelling of subducted oceanic plate with variable effective elastic thickness along the Manila Trench, Geophys. J. Int., 215(3), 20712092.

Zhou, Z. \& Lin, J., 2018. Elasto-plastic deformation and plate weakening due to normal faulting in the subducting plate along the Mariana Trench, Tectonophysics, 734-735, 59-68.

Zhou, Z., Lin, J., Behn, M.D. \& Olive, J.-A., 2015. Mechanism for normal faulting in the subducting plate at the Mariana Trench, Geophys. Res. Lett., 42(11), 4309-4317.

\section{SUPPORTING INFORMATION}

Supplementary data are available at $G J I$ online.

Figure S1. Magnitude differences of reported earthquakes in the southern Mariana subduction zone between the USGS and the International Data Center (IDC) catalogue.

Figure S2. (a, b) The distribution of horizontal and vertical uncertainties of absolute locations versus distances. (c, d) Histogram distribution of horizontal and vertical uncertainties of absolute locations.

Figure S3. Map of background seismicity using the International Seismological Centre (ISC) catalogue during 1962-2018.

Figure S4. The slab geometry in the southern Mariana based on SLAB2.0 model. All located earthquakes (circles) are plotted.

Please note: Oxford University Press is not responsible for the content or functionality of any supporting materials supplied by the authors. Any queries (other than missing material) should be directed to the corresponding author for the paper. 